\title{
Evolución de la polarización territorial de la producción web: ¿para cuándo la esperada descentralización?
}

\section{Evolution of the territorial polarization of web production: when will the so-called decentralization happen?}

DJAMEL TOUderT*

\begin{abstract}
The polarization of web content production in evolutionary terms raises some questions for understanding the territorial appropriation of Information and Communication Technologies (ICT). One of them concerns the breadth of the territorial diffusion following strategies in order to deal with digital breaches, and the other is framed in the different evolution paths of regional polarization in developed and emerging countries. These two interests, examined in the core of first-level territorial divisions of the eight countries involved in the study, revealed undifferentiated contexts with persistent macrocephaly and an absent intra-regional convergence of web production.
\end{abstract}

Keywords: web contents, territorial polarization, macrocephaly, territorial convergence, emerging and developed countries.

\section{Resumen}

La polarización de la producción de contenidos web plantea, en términos evolutivos, interrogantes para el entendimiento de las dinámicas territoriales de la apropiación de las Tecnologías de la Información y las Comunicaciones (TIC). Una de ellas se refiere a la amplitud de la difusión territorial como consecuencia de estrategias encaminadas a lidiar con las brechas digitales, y la otra se enmarca en diferentes trayectorias de evolución de la polarización territorial en países desarrollados y emergentes. Estos dos intereses fueron analizados en el seno de las divisiones territoriales de primer nivel de los ochos países involucrados en el estudio y revelaron, en contextos indiferenciados, la persistencia de la macrocefalia y una ausente convergencia intra-regional de la producción web.

Palabras claves: contenidos web, polarización territorial, macrocefalia, convergencia territorial, países desarrollados y emergentes.

\footnotetext{
* El Colegio de la Frontera Norte. Correo-e: toudert@colef.mx
} 


\section{Introducción}

La importancia alcanzada por la web ${ }^{1}$ se refleja de manera indiscutible en el crecimiento de sus contenidos creados y el número de los usuarios que llegan a conectarse también a las demás aplicaciones de la internet como el correo electrónico y las redes sociales. Después de dos décadas de su inicial lanzamiento, la web cuenta con más de 312 millones de sitios y una población de usuarios estimada a un poco más de $28 \%$ de la población mundial. ${ }^{2}$

Contrariamente al inicio, caracterizado por la preeminencia de un enfoque global en la creación de contenidos, otro tipo de usuarios se han ido sumando al uso de la web quienes, a su vez, le han proporcionado cada vez más pertinencia a un creciente anclaje local y regional. En este sentido, sin desconocer el atractivo global de una considerable oferta de la web, los usuarios parecen expresar una preferencia inigualable por los contenidos de proximidad identificados por la cercanía geográfica y sus identidades lingüísticas y culturales (Dodge y Shiode, 2000; Toudert y Buzai, 2004; Zook, 2005).

La afirmación anterior no pretende abreviar la compleja relación entre el contenido web y su ubicación geográfica, sino robustecerla a partir de la discusión que puede llegar a expresar un conocimiento generalmente localizado de cara a la ubicuidad de la producción y al consumo de la internet.

No obstante, pese a la emancipación de la tiranía del espacio que le concede todavía el discurso dominante a la apropiación productiva de las Tecnologías de la Información y las Comunicaciones (TIC), la polarización territorial de la producción de la web sigue siendo -entre otras cosas- una expresión retadora para el conocimiento geográfico (Graham, 1998; Kellerman, 2002). En efecto, las ciudades capitales, regiones metropolitanas prominentes y zonas urbanas dominantes parecen seguir avasallando con las producciones nacionales de la web.

En México, durante el 2004, más de la mitad de la producción nacional de la web fue elaborada en el Distrito Federal (DF), y esta tendencia

\footnotetext{
${ }^{1}$ En este trabajo el término web refiere a la World Wide Web, enfocándose principalmente, a los contenidos accesibles a la consulta pública. Los conceptos de web producida o de contenidos web producidos en los diferentes países involucrados en el estudio se emplean exclusivamente para distinguir a los dominios registrados ante los respectivos Internet Network Information Centers nacionales. El impacto de la producción local de dominios registrados a nivel internacional con relación a los registrados nacionalmente constituye una proporción marginal y no parece estructurar una fuente de variación sustancial en las participaciones locales a la producción nacional de dominios web (Toudert, 2007; Zook, 2000 y 2001).

${ }^{2}$ Según datos de Netcraft e Internet World Stats, disponibles en <news.netcraft.com > y <www. internetworldstats.com>, respectivamente, 8 de abril 2011.
} 
dominante no parece mostrar signos claros de redistribución hacia otras entidades del país (Toudert, 2007).

En este sentido, la polarización no parece ser el reflejo temprano de un fenómeno nacido con intrínsecos atributos de difusión territorial ni tampoco tiende a confinarse en un grupo específico de países o de experiencias regionales en la apropiación socioterritorial de las TIC. En el marco de estos contextos polarizados, las políticas y acciones puestas en marcha por parte de los diferentes actores que lidian con la dimensión territorial de la brecha digital no parecen haber sido exitosas en revertir las tendencias observadas durante los inicios de la web.

A nivel internacional, la polarización territorial y su dinámica temporal favorecen el surgimiento de interrogantes planteadas con el interés de identificar similitudes y diferencias en la distribución territorial interna de la producción de contenidos en países desarrollados y emergentes.

En efecto, tanto el conocimiento publicado sobre el tema en particular como los supuestos basados en el análisis de las variables sugieren una posible conformación del espacio productivo de la web, distinguiendo dos grupos de países (Toudert, 2007 y Toudert et al., 2008).

Conjeturar acentuadas polarizaciones en los países emergentes, basándose en las diferencias multifactoriales de la apropiación de las TIC y la producción de la web en las demarcaciones territoriales internas, constituye un intento razonable de mejorar el estado del conocimiento en temas generalmente poco aproximados por la investigación.

No obstante, más allá del lado concurrente y atractivo del supuesto anterior para el discurso de la equidad, resulta pertinente indagar, por medio de casos reales, si los altos niveles de polarización son un rasgo intrínseco al desarrollo de la web en los países emergentes o si lo observado en el caso mexicano constituye la excepción en un contexto internacional más bien indiferenciado (Toudert, 2007 y Toudert et al., 2008).

$\mathrm{Al}$ considerar la evolución temporal de lo territorial en la producción de los contenidos nacionales es importante averiguar si los altos niveles de polarización presentados en los inicios de la web se caracterizaron por una creciente redistribución a favor de las entidades no centrales. Este último supuesto se presenta como propicio a las entidades periféricas y se presta a una construcción relacionada con el comportamiento productivo en países desarrollados y emergentes que, por cierto, corresponde aclarar.

En este sentido, la convergencia intrarregional se beneficia del factor tiempo, estimado necesario para la difusión y el aprendizaje tecnológico, y permite presumir una reducción sostenida en las brechas productivas que caracterizan a las entidades de cada país.

Desde luego, la convergencia regional se encuentra también suspendida en un marco evolutivo desigual a la estructura y a los componentes 
de una polarización que suele también caracterizarse desde la perspectiva de países desarrollados y emergentes (Toudert, 2007).

El presente trabajo consta de tres secciones: la primera está dedicada a ubicar, en el marco de la discusión disciplinaria, la evolución de la polarización en la producción de contenidos de la web; en la segunda se explicarán los métodos, datos e instrumentos que permitieron darle sustento empírico al conjunto de las pesquisas en el estudio; en la tercera se expondrá, desde una perspectiva articuladora, la discusión de los resultados del análisis de la microcefalia, la estructura de dispersión y la convergencia intrarregional que permiten resaltar las similitudes y diferencias que han caracterizado la evolución de la producción web en los diferentes países involucrados en el estudio.

\section{Evolución de la polarización territorial de la producción web: hacia una aproximación conceptual razonable}

Buscar la inserción conceptual de la evolución de la polarización territorial en la producción web constituye una ardua tarea por lo reciente del sujeto de estudio y el entendimiento todavía parcial de los componentes del entorno, como son la apropiación socioterritorial de las TIC y las lógicas involucradas en la creación de la web.

Al tomar en cuenta estas limitaciones quizá es importante aclarar que este trabajo no procura profundizar sobre las debilidades epistemológicas y conceptuales que dificultan el estudio de la producción web; tampoco pretende esclarecer los orígenes y mecanismos que rigen el fortalecimiento de la polarización territorial, puesto que estos aspectos necesitan por sí solos una investigación que va más allá de la presente contribución. ${ }^{3}$

El estudio de la polarización territorial en la producción de la web parece cobrar un interés de investigación al establecer conceptualmente una correspondencia entre la creación de sus contenidos y la integración socioterritorial a los diferentes postulados de la sociedad de la información (Graham, 1998; Castells, 2002). Como se explicará más adelante, independientemente de la ubicuidad de los flujos de información, la segmentación socioterritorial de la producción y consumo de la web se convierte en un contexto atrayente para el desarrollo de, entre otras, las tesis modernistas y posestructuralistas de la apropiación socioterritorial de la internet.

Estos entornos de producción y consumo de la web son un terreno de predilección para la adopción de estrategias y la aplicación de políticas,

\footnotetext{
${ }^{3}$ No obstante, estos intereses temáticos y epistemológicos, en lo que toca al debate disciplinario, fueron regularmente revisados e incorporados en Toudert y Buzai (2004); Toudert (2007) y Toudert et al., 2008.
} 
generalmente voluntaristas, concebidas para revertir las condiciones que ha propiciado la ampliación de la brecha digital en sus diferentes dimensiones y modalidades (Paradiso y D'Aponte, 2003). De esta manera, el análisis de la evolución de la estructura territorial en la producción web encuentra su razón en lo afirmado anteriormente y, además, da seguimiento, en gran medida, a reflexiones e interrogaciones expresadas en trabajos anteriores (Toudert, 2007 y Toudert et al., 2008).

\subsection{Antecedentes y contextualización del estudio}

La investigación publicada sobre la distribución territorial de la producción web en México (Toudert, 2007) permitió poner de relieve, durante 2004, una concentración de $75 \%$ de la producción nacional de dominios en las entidades del Distrito Federal, Nuevo León y Jalisco, 55\% del cual corresponde al DF. Estos altos niveles de participación en la producción nacional que identificaron principalmente a la entidad capital tuvieron una tendencia a la alza a través de un crecimiento de cerca de dos puntos porcentuales entre 2000 y 2004.

En términos comparativos a nivel internacional, el contraste de la distribución territorial en la producción de dominios en México, Estados Unidos (Moss y Townsend, 1997 y 2000; Kolko, 2000) y en varias ciudades del mundo (Zook, 2000 y 2001) llevaron a Toudert (2007) a plantear la sospecha de una posible polarización diferenciada entre países desarrollados y emergentes.

En efecto, los niveles de polarización de la producción de dominios en las entidades capitales con respeto a sus espacios nacionales dejaba entrever en el DF una concentración que era 1.82 veces más que en Londres, 2.12 veces más que París y 3.23 más que Berlín, Munich y Hamburgo juntas (Toudert, 2007 y Zook, 2001).

Además, resulta también interesante constatar que, mientras la concentración en el DF siguió creciendo entre 2000 y 2004, la participación del estado de California con respecto a las demás entidades de la unión americana bajó 4.5 puntos porcentuales entre 1998 y 2001, mientras que la contribución de Berlín, Hamburgo y Munich en su espacio nacional, pese a su nivel relativamente bajo, descendió casi un punto porcentual entre 2000 y $2004 .{ }^{4}$

Lo anterior, obviamente contextualizado en una época de carencia de datos suficientes, mostraba, por un lado, un excesivo nivel de polarización de los lugares dedicados a la producción de dominios en México que

${ }^{4}$ Cálculo para Estados Unidos realizado con datos del conteo de dominios provenientes de la base de datos del doctor Matthew Zook. En el caso alemán se usaron datos del top-20 Kreis de DENIC-eG. 
representaba un ejemplo de nación emergente y, por el otro, en países desarrollados la alta polarización territorial que parecía daba paso a una transferencia progresiva a otras entidades, en México la tendencia temporal favorecía la concentración territorial (mapa 1).

Estos acontecimientos observados abrieron camino a otro supuesto que sostiene que lo hallado en el caso mexicano no parecía encajar en la explicación de la polarización territorial en los países desarrollados ${ }^{5} \mathrm{y}$, por lo tanto, se anticipó la justificación de una tesis alternativa para aclarar estas singularidades (Toudert, 2007 y Toudert et al., 2008).

En el contexto internacional de los inicios de la internet como bien público, tanto la geografía como las demás disciplinas de las ciencias sociales trataron de descifrar las lógicas de producción de la web, principalmente desde el prisma de la sociedad estadounidense. De hecho, los hallazgos que acompañaron estos nacientes intereses epistemológicos iluminaron las aportaciones teóricas sustentadas en el arbitraje empírico y, sobre todo, fortalecieron una eficiente crítica a las tesis ciberespaciales fundadas en la proclamada muerte de la geografía (Gaspar y Glaeser, 1998; Cairncross, 1997 y 2001).

En el marco de estas contribuciones, los empiristas críticos de primera generación lograron posicionar el tema de la producción web en el seno de la discusión tradicional sobre las jerarquías metropolitanas y urbanas que parecen caracterizar a la organización territorial funcional de los países estudiados. ${ }^{6}$

Estos estudios fueron encabezados por pocos geógrafos, salvo el análisis realizado por Zook (2001) que implica una base de datos de 2,500 ciudades mundiales; el interés académico para comprender la estructura territorial de la web en los países emergentes era casi inexistente.

Por un lado, la producción de la web de los países desarrollados y específicamente de Estados Unidos era abrumadoramente más grande comparada con los países emergentes y, por otro, lo que más urgía en el conocimiento académico era abrir una brecha inicial a nivel global. Bajo esta lógica era previsible y hasta legítimo centrarse en unos cuantos países desarrollados que saturaban los contenidos de la web.

No obstante, es importante mencionar que, cuando los países emergentes fueron incluidos en los pocos estudios realizados, se logró destacar casos atípicos como el hallazgo de una excesiva polarización de la produc-

\footnotetext{
${ }^{5}$ Explicaciones que caracterizaron a los trabajos de geógrafos estructuralistas como en Moss y Townsend, (1997 y 2000); Kolko (2000); Zook (2000 y 2001) y Kellerman (2002), entre otros.

${ }^{6}$ Los empiristas críticos de primera generación, de acuerdo a como se les definió en Toudert, (2007 y 2008), se enfocaron a reivindicar la dimensión territorial en la producción de la web a través de estudios de casos basados, generalmente, en el análisis de bancos de datos generados por proyectos universitarios y empresariales, véase trabajos de Moss y Townsend (1997 y 2000); Kolko (2000); Dodge y Shiode (2000); Zook (2000 y 2001).
} 


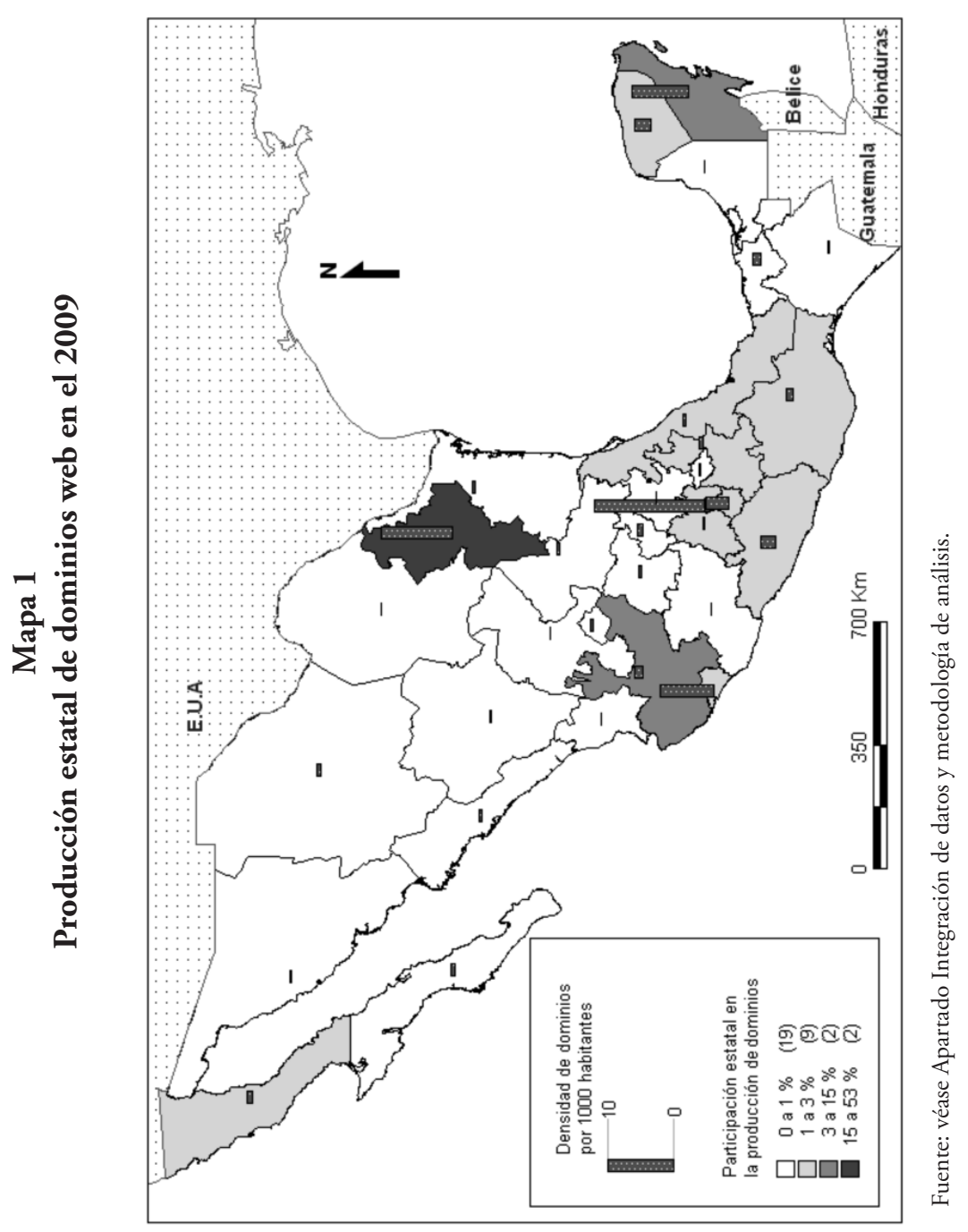


ción en México y el ejemplo de la producción web de Corea del Sur que llegó a rivalizar con ciudades del viejo continente (Zook, 2001; Toudert y Buzai, 2004 y Toudert, 2007).

En este sentido, la inclusión de países emergentes en los estudios de la producción territorial de la web se vuelve significativa para un mejor entendimiento del papel de lo local en la sociedad de la información, donde las TIC y su producción son consideradas, por el discurso dominante, un catalizador de la equidad territorial (Graham, 1998; Cairncross, 2001; Stimson et al., 2009).

\subsection{Dinámica global-local y la importancia de la producción autóctona de contenidos}

Comparado con los múltiples estudios que se enfocaron desde la geografía y sus disciplinas hasta la cobertura de las Tic y la accesibilidad de los diferentes grupos sociales a la red y sus respectivos impactos socioterritoriales, la investigación de la producción de contenidos web fue marginal, y ciertamente sus hallazgos no parecen haber logrado difundirse como una alternativa popular al discurso ciberespacial.

En estos contextos marcados todavía por los misterios que envuelven a la web, la relación territorial de la producción y consumo de sus contenidos constituye un tema central para la comprensión de las lógicas de la inserción local en la sociedad de la información.

La búsqueda de una cierta simetría entre la producción y sus espacios locales en el contexto de la sociedad de la información fue una perspectiva visitada de manera concreta durante los ochenta por Masuda (1980), Kellerman (1985), Antonelli (1986) y Dosi (1988). Al igual que la mayoría de la literatura enfocada a la geografía de las telecomunicaciones, en la década mencionada dominaron los estudios de impacto socioterritorial de las TiC y los flujos de información que generan (Toudert et al., 2008).

Con el advenimiento de la web y su rápida adopción por millones de usuarios en los inicios de los noventa, se cristalizaron nuevos intereses temáticos y epistemológicos estructurados alrededor de la dualidad espacio/ciberespacio en contextos territoriales dominantes y de creciente penetración social de las Tic (Graham y Marvin, 1996; Eveno, 1997; Wilson y Corey, 2000; Kellerman, 2002; Schmidt, 2014).

En paralelo a estos intereses fortalecidos en el marco de las contribuciones que se dieron en el seno de la Comisión de Geografía de la sociedad de la información de la Unión Internacional de Geografía, se abrió una importante brecha por parte de los empiristas críticos de primera generación quienes relacionaron por primera vez ciudades y espacios metropoli- 
tanos con la producción y el consumo de la web (Moss y Townsend 1997 y 2000; Kolko, 2000; Dodge y Shiode, 2000; Zook, 2000 y 2001).

En este sentido, equiparar la producción local de la web con el número de registros de dominios de internet ${ }^{7}$ en la misma área fue un acercamiento conceptual razonable que permitió visualizar territorialmente a la web, relacionando su producción con su consumo por parte de los usuarios (Zook, 2005; Toudert et al., 2008).

Estos arreglos conceptuales y metodológicos también permitieron ver con claridad que la producción de la web llegaba a moldearse en el seno de las jerarquías territoriales existentes en lugar de inducir la descentralización tan pronosticada por los gurús del ciberespacio (Zook, 2000 y 2001; Kellerman, 2002; Toudert, 2007).

La polarización territorial en la producción de la web aparece como un hecho intrínseco al desarrollo de la internet y sus dinámicas de generación, transmisión y consumación de contenidos en un contexto organizacional, cada vez más centrado en la información que adquiere el estatus de materia prima (Kellerman, 2002; Hashimoto, 2002). A partir de los trabajos de Kolko (2000) y Zook (2000) quedó establecido que la importancia de los contenidos producidos en la web se ajustaban a las jerarquías de los sistemas urbanos y metropolitanos propios de cada nación, enfatizando en dichas localizaciones identificadas por niveles apreciables de interconexión a una capacidad productiva proporcional al tamańo poblacional.

Lo anterior mostraba también un cierto empate de localización entre las significativas zonas de producción de la web y los importantes polos financieros que aglutinan a destacados atributos de innovación, conocimiento y liderazgo en la toma de decisiones (Castells, 2002; Zook, 2005). Estos contextos de polarización llegan también a exhibir, en casos específicos, diferencias con las lógicas descritas anteriormente pero, aun así, no logran posicionarse como una excepción a la regla y, además, los contenidos generados parecen estar emancipados de las vocaciones tradicionales de cada plaza (Zook, 2005; Toudert et al., 2008).

La compleja relación existente entre la web y sus respectivos territorios de generación puede verse en el marco de las diversas limitaciones de accesibilidad a los contenidos creados tanto adentro como afuera de los alcances lingüísticos y culturales de los usuarios. En efecto, en un contexto de oferta global competitiva, un consumo devoto a los contenidos

\footnotetext{
${ }^{7}$ Un dominio consiste en una dirección nominal que enlaza los usuarios con los contenidos de uno o más sitios web. Generalmente, el dominio web es la asociación del nombre de la organización propietaria de un dominio genérico (.com, .gob, etc.) y un dominio de alto nivel que representa al país de registro del dominio en cuestión (.mx, para México, .fr para Francia, etc.). El detalle de los aspectos conceptuales y metodológicos del involucramientos de los dominios web en investigaciones con propósitos cercanos pueden revisarse en Toudert y Buzai (2004); Toudert (2007) y Toudert et al. (2008).
} 
locales, además de satisfacer a la demanda de un segmento específico, otorga factibilidad a una web que no pretende renunciar a la ampliación global de su base de usuarios, independientemente de sus características y preferencias (Dodge y Kitchin, 2001; Zook y Graham, 2007).

En este sentido, los contenidos autóctonos de la web desempeñan un papel significativo en el balance global-local de la apropiación socioterritorial de las TIC, mientras algunas de sus dinámicas fueron puestas en evidencia por los empiristas de segunda generación, principalmente en lo que corresponde a bienes y servicios no materiales como en el caso de los contenidos relacionados con gustos y preferencias de usuarios (Forman et al., 2005; Greenstein, 2006; Toudert et al., 2008; Schmidt, 2013).

Independientemente de la indudable importancia de la producción local de contenidos y su impacto en la demanda de usuarios, la polarización territorial en la producción sigue siendo un rasgo característico de la dinámica global-local.

Bajo esta lógica, cuando las políticas de desarrollo y las estrategias de planeación de las TIC son vistas como factores que cambian el esquema de crecimiento territorial de las redes de la internet y sus usuarios (Townsend, 2003) es quizá pertinente preguntarse si también acarrean cambios significativos en la estructuración territorial de la producción web.

Desde esta misma perspectiva y tomando en cuenta la estructura territorial de la producción web, sería interesante averiguar si los cambios advertidos en los países desarrollados se dan de manera indiscriminada en los países emergentes que, por cierto, están también en el contexto de aplicación de políticas de desarrollo y planeación de las Tic.

\subsection{Políticas de fomento a la apropiación de las TIC y evolución de la polarización territorial}

A partir de su ingreso a la esfera del consumo de masa a nivel global, la internet logró colocarse rápidamente en el centro del discurso sobre el desarrollo territorial en sus diferentes vertientes y escalas. En estos contextos, contrariamente a las demás herramientas de las TIC que se perciben como simples medios o artefactos como el teléfono, la internet es apreciada como la señal de un nuevo modelo de sociedad esculpido en la modernidad (Graham, 1998, Castells, 2002).

Lo anterior traduce la valoración favorable hacia las Tic. Más allá de las frustraciones que acompañan a los proyectos voluntaristas centrados en la internet, la fascinación por estas herramientas sigue siendo más fuerte y su poder desarrollador es pocas veces cuestionado por los actores del desarrollo (Bertrand, 2001). 
El embrujamiento que producen estas herramientas permea la relación entre los actores del desarrollo y la apropiación socioterritorial de la internet y provoca una conceptualización simplista que provee material necesario para estructurar diversas concepciones como las referidas a la economía digital y su corolario: el comercio electrónico.

De manera general, la conceptualización del desarrollo territorial de la internet en el marco de las tesis modernistas y neoliberales de la teoría económica sirve de lecho a una argumentación progresiva que concibe a la reducción de la brecha digital como pase automático para disminuir las diferencias socioterritoriales en otros ámbitos (Graham, 2008). De igual manera, la perspectiva crítica del desarrollo, amparada principalmente en tesis postestructuralistas y postcolonialistas, ubica a la brecha digital como una desventaja que nace del antagonismo histórico entre los países que son desarrollados y los que no.

No obstante, si para Escobar (1995) y Schech (2002) la integración digital encarnaría la intensificación de la hegemonía multidimensional inherente a la mundialización del capitalismo, para Esteva (1987), Grimes (2003) y Stimson et al. (2009) la alienación se origina más bien en la imposición extraterritorial y jerárquica, al resaltar los beneficios de una apropiación endógena de las Tic.

En este sentido, la relación entre el impulso endógeno y exógeno constituye un punto de referencia en la contribución crítica del posdesarrollo que, por cierto, coincide con la corriente modernista al otorgarle a la brecha digital un lugar preponderante en el entendimiento de las lógicas de apropiación socioterritorial de las Tic.

La brecha digital como un concepto sintomático multidimensional encarna, al mismo tiempo, las dificultades que enfrenta la cristalización de un ideal de equidad en la apropiación socioterritorial de las Tic y los contextos resultantes de estos procesos de integración. Bajo esta amplia caracterización, la brecha digital aparece como un concepto nebuloso de difícil abordaje epistémico, aun cuando se le reconoce una apreciable aptitud metafórica para referirse a contextos de marginación socioterritorial en la era digital (Castells, 2002; Keniston y Kumar, 2004; Toudert, 2005).

La noción de brecha digital insertada en un espectro de discursos, propósitos y proyectos de integración territorial y comunitaria basados en las Tic fue muy pronto acomodada en la jerga gubernamental y puesta en la canasta de pendientes de las instituciones de desarrollo de los diferentes ámbitos de intervención y autoridad territorial.

De esta manera, el imperativo de la integración a la era digital adquirió una posición importante en la agenda de los actores del desarrollo, expresándose a través de programas y planes especiales encaminados a superar las deficiencias en la infraestructura física e incrementar rápida- 
mente la penetración social de las TIC (Graham y Marvin, 2001; Toudert, 2003; Massey, 2005; Denardis, 2014).

Bajo estos impulsos, tanto en países desarrollados como emergentes se pusieron en marcha proyectos multimillonarios de desarrollo de las TIC que fueron generalmente complementados, apoyados o impulsados por organizaciones internacionales que llegaron a desempeñar a veces el papel de principales promotores de la conectividad a la red global (Norris, 2001; BM, 2005).

Como ejemplo de estos proyectos en países emergentes, a partir del 2002 se firma en México el Convenio de conectividad e-México, que tenía contemplado incrementar la conectividad social a través de los Centros Comunitarios Digitales y crear contenidos en sus cuatro componentes: e-aprendizaje, e-salud, e-economía, e-gobierno (Toudert, 2005). Desde la fecha de su puesta en marcha, aunque el paisaje de la internet en México ha cambiado significativamente tanto en el número de usuarios como en el tamaño y diversidad de sus contenidos, el impacto de e-México en dichas dinámicas no parece determinante (Toudert et al., 2008).

No obstante que e-México fue iniciativa del gobierno federal, tomaron posición una infinidad de otros proyectos públicos y privados que se fundamentaron, entre otras cosas, en la reducción de la brecha digital entre espacios, comunidades, etnias y hasta individuos. En efecto, tanto en México como en otros países la convergencia entre las lógicas de interés y de valores no puede considerarse ajena al acelerado crecimiento de la apropiación social de la red (Norris, 2001; Castells, 2003).

Al tomar como ejemplo a los países involucrados en el presente estudio, la evolución de las variables de penetración social de la internet y la creación de contenidos deja entrever altas tasas de crecimiento independientemente del contexto desarrollado o emergente que puede caracterizar a estas naciones.

Para el conjunto de estos países, entre el 2000 y 2009, en promedio los usuarios de la internet crecieron con una tasa media anual de $23 \%$, la suscripción a la banda ancha fija de $100 \%$ y los dominios registrados de 15\% (cuadro 1).

Estos porcentajes que describen un desarrollo acelerado pueden reflejar, también en los países emergentes, una apropiación de la internet por pequeños universos de usuarios de cara a la población total, hecho que traduce cambios no tan importantes en altas tasas de crecimiento.

En el marco de estos contextos caracterizados por altos indicadores de crecimiento de la apropiación social de la internet a nivel de país, resulta interesante averiguar si las divisiones territoriales internas tuvieron el mismo comportamiento en condiciones de una razonable equidad. 


\section{Cuadro 1 \\ Tasa de crecimiento medio anual de indicadores de la internet por 100 habitantes (2000-2009)}

\begin{tabular}{lccc}
\hline \multicolumn{1}{c}{ Paises } & Usuarios de internet & $\begin{array}{c}\text { Suscripciones a banda } \\
\text { ancha fija }\end{array}$ & Dominios registrados \\
\hline Alemania & 11.31 & 65.86 & 6.17 \\
Brasil & 33.72 & 66.56 & 53.65 \\
China & 36.30 & 154.93 & 90.63 \\
Corea & 6.92 & 17.21 & 7.92 \\
México & 21.03 & 96.69 & 23.54 \\
Paraguay & 41.81 & 117.96 & 33.70 \\
Rusia & 34.75 & 229.51 & 30.28 \\
Suiza & 5.07 & 52.62 & 15.55 \\
\hline
\end{tabular}

Fuentes: los datos de usuarios de internet y suscripción a banda ancha provienen de la Unión Internacional de Telecomunicaciones, World Telecommunication/ICT Indicators Database. La información relativa a la población procede del U.S. Census Bureau, International Data Base. El conteo de los dominios registrados se genera por el Network Information Center (NIC) de cada país.

Lo anterior adquiere una importancia fundamental considerando que los inicios de la internet se caracterizaron por una marcada polarización territorial tanto en los usos como en los contenidos creados. En este sentido, indagar si con el paso del tiempo las altas tasas de crecimiento han logrado mitigar la polarización territorial permite también apreciar la contribución de las políticas para lidiar con la brecha digital en su dimensión territorial.

Para dejar de apuntar a la internet en su totalidad y enfocar de manera prioritaria a la producción de contenidos de la web que abarca específicamente esta investigación, resulta importante examinar el alcance de las políticas y los instrumentos de desarrollo puestos a contribución para cerrar la brecha digital en materia de regiones de producción web.

Bajo esta perspectiva, el cuestionamiento es si las políticas públicas e iniciativas privadas han beneficiado también a las divisiones territoriales internas al igual que le hicieron a nivel nacional, o si durante este periodo de crecimiento se consolidaron aún más los liderazgos territoriales tradicionales en la producción web.

A dos décadas del inicio de la web como una de las redes más populares de la internet, la producción de sus contenidos constituye todavía un sujeto de estudio muy difícil de construir sin recurrir a complejos recursos de investigación que pueden llegar inclusive a dificultar la extensa difusión de sus hallazgos. 
De hecho, con el paso del tiempo, la modelación conceptual y los instrumentos de exploración empleados se volvieron más complicados, reflejando, por cierto, la complejidad que ha venido caracterizando la evolución de la web y sus lógicas de estructuración de contenidos.

Con la finalidad de sobrepasar varias de estas limitaciones, el presente estudio se realizó en contextos nacionales identificados por datos disponibles, a través de un enfoque epistemológico razonablemente aceptado en el seno de la disciplina.

\section{Integración de datos y metodología de análisis}

Salvo el conteo de dominios registrados en México que fue elaborado bajo el procedimiento metodológico divulgado en Toudert y Buzai (2004), Toudert (2007) y Toudert et al. (2008), los datos analizados tienen su origen en los respectivos organismos de registro de dominios de la internet de cada país (NICs: Network Information Centers).

Como se observa en el cuadro 2 , se analizaron datos de dominios de la web registrados en el marco de las divisiones territoriales de primer nivel que caracterizan a cada uno de los ochos países que integraron el estudio. Para la mitad de los países involucrados se analizaron datos registrados año tras ańo durante una década (desde 1999 a 2009), y en el caso de los cuatro restantes se optó por las técnicas de retrospectiva y proyección para completar la información faltante durante periodos específicos.

Globalmente, para la estimación del número de dominios durante uno o varios años se procedió por medio del cálculo y la proyección de la densidad de dominios por 1,000 habitantes, apoyándose en la existencia del dato poblacional o su estimación en el caso de ausencia de la información. Lo anterior introduce, desde luego, una fuente de imprecisión que se intentó subsanar recurriendo a modelos de proyección que cumplen con los supuestos de normalidad, autocorrelación y homocedasticidad.

No obstante, a pesar de las precauciones técnicas tomadas para reducir la imprecisión, no se puede afirmar tajantemente que el presente estudio es inmune a la inferencia de posibles defectos en la estimación de datos faltantes. En este sentido, en lo que toca al estudio de dominios de la web, la carencia de datos puede ser una de las consecuencias del reducido conocimiento básico sobre la dinámica de los contenidos en general y, en el seno de los países, en particular.

La escasez de datos que sustenta la carencia de conocimiento de la web se refleja también en una disponibilidad limitada de la información de registros de dominios web circunscritos territorialmente. En efecto, la disponibilidad de este tipo de información territorial fue el criterio principal de la selección de países incluidos en la presente contribución. De 


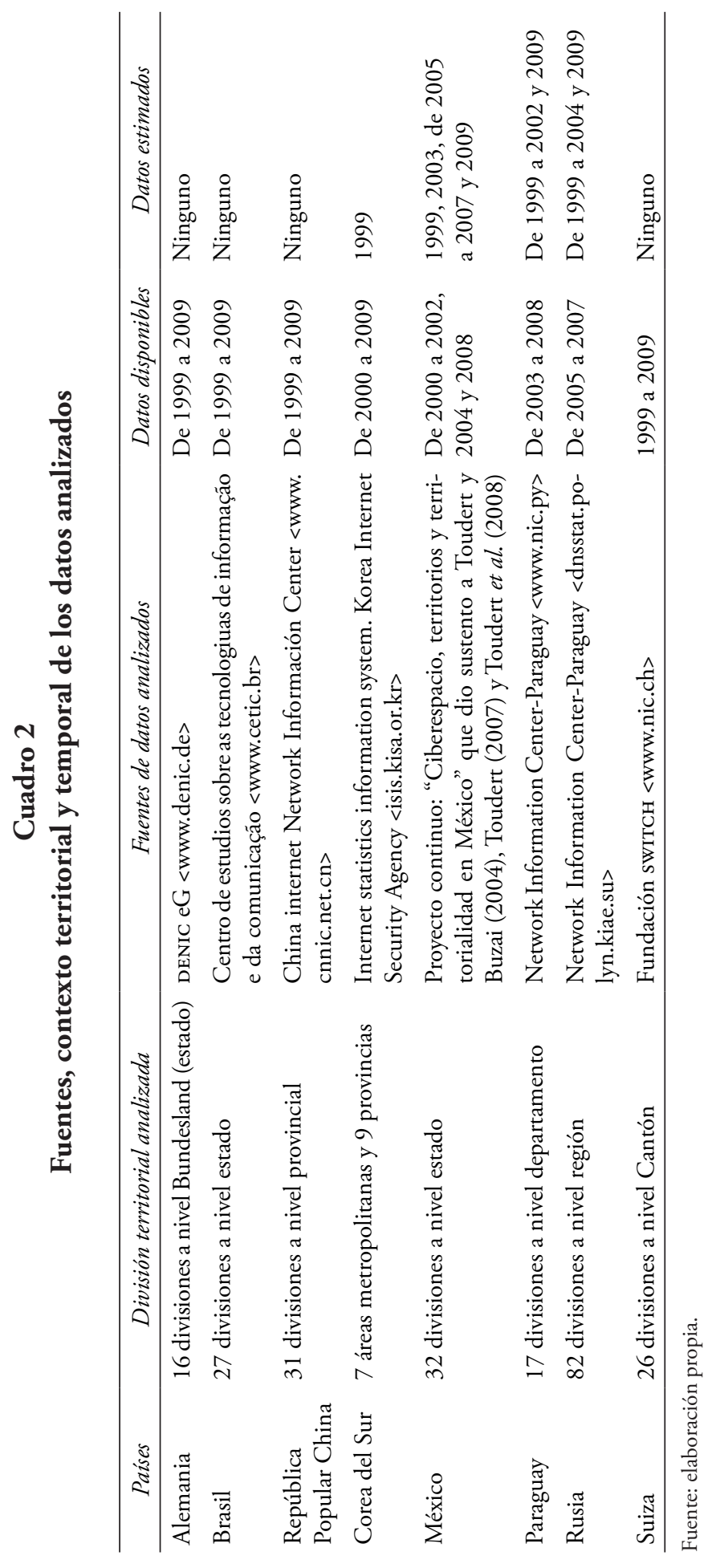


hecho, salvo el caso de México que fue integrado al estudio gracias a una relativa disponibilidad de antecedentes de generación de la información requerida (Toudert, 2008), todos los países que publican estadísticas de dominios en el marco de sus divisiones territoriales fueron seleccionados.

En este sentido se eligieron ocho países que disponían de un conteo territorial de dominios; por una cuestión de homogenización de las condiciones de estudio, esta información tenía que coincidir, por lo menos, con la división espacial de primer nivel y abarcar, en la medida de lo posible, el periodo de estudio comprendido entre 1999 y 2009.

Tratar de lograr la exploración más completa posible de la estructura de polarización territorial de la producción web nos encaminó a la confección de una plataforma de lectura elaborada con tres pruebas que permiten, en su conjunto, caracterizar a posibles perfiles de polarización.

Lo anterior se desprende del supuesto que permite posicionar la polarización territorial en la producción web como un hecho susceptible de traducirse en perfiles segmentados, no nada más por la amplitud de la concentración de la producción sino también por la estructura que expresa dicha polarización. De esta manera, el análisis de la producción territorial de dominios web permite a los países involucrados en el estudio ser caracterizados desde una perspectiva comparativa por cada uno de los tres indicadores calculados, destacando así las diferencias y similitudes entre países analizados.

En el marco de esta lógica de articulación de las observaciones que se desprenden del cálculo de indicadores, se inició el análisis integral con una prueba de macrocefalia cuyo método se asemeja al cálculo del indicador de primacía, seguido por una exploración de la estructura de dispersión aproximada a través del cálculo de los coeficientes de variación inherentes a cada uno de los países incluidos en el estudio.

Estos tratamientos estadísticos encaminados a facilitar el entendimiento de la estructura de la polarización fueron profundizados por medio de un estudio de la convergencia regional de la producción de dominios web y un escudrińamiento de la dinámica de las desigualdades regionales en el seno de los países involucrados en el estudio.

El análisis del grado de macrocefalia de la producción de dominios mide la relación de la región con la producción más alta entre su equivalente en las tres regiones que la siguen en la clasificación. De esta forma, el grado de macrocefalia refleja tanto el nivel de polarización como el estado de la supremacía de la primera región respecto a las demás regiones de cada país. De manera concreta, el grado de macrocefalia traduce el desfase en términos de producción de contenidos web que separa, generalmente, las capitales del resto de las demás entidades en cada país. 
En el marco de estos entornos nacionales, el análisis, desde una perspectiva comparativa de la estructura de dispersión, permite lograr un acercamiento de la heterogeneidad territorial de esta producción en los países de estudio. En este sentido, el uso de los coeficientes de variación (cv), calculados para un periodo comprendido entre 1999 y 2009 por medio de la relación de la desviación estándar entre el promedio de la producción de dominios por las divisiones de primer nivel de los países estudiados, permitirá aclarar los matices de la polarización territorial observada. Además, al tomar en cuenta el conocimiento que arroja el análisis del grado de macrocefalia, se avanza también en la identificación de los esquemas de polarización que se dan en un país con respecto a los demás.

En medio de las diferencias de estructuración de la producción web, en cada país involucrado en el estudio se impone el análisis de la heterogeneidad territorial de la producción que conlleva de manera natural a preguntarse si las diferencias regionales observadas dejan entrever una perspectiva temporal convergente o divergente, resultado de la ampliación de las brechas entre las diferentes regiones que los componen.

Para aportar elementos de respuesta a la pregunta anterior se realizó el cálculo para el periodo 1999-2009 del indice de convergencia sigma ${ }^{8}$ que permite medir el grado de desigualdades existentes en la producción de dominios web de las diferentes regiones que componen los países estudiados.

\section{Resultados y caracterización de la evolución de la polarización territorial de la producción web}

La discusión de los resultados de la evolución de la estructura de polarización territorial en el contexto de los países involucrados en el estudio se llevó a cabo a partir de tres ángulos complementarios que permitieron resaltar las similitudes y diferencias que caracterizaron la producción de contenidos web entre 1999-2009.

Se inicia con la exposición de los hallazgos referentes a la evolución de la macrocefalia regional y posteriormente se explora la dinámica temporal de la dispersión territorial y la discusión de la convergencia intrarregional, para finalizar con una reflexión de conjunto que permite enfatizar las aportaciones que logra destacar el presente estudio.

\footnotetext{
$\left.\sigma=\sum_{\mathrm{i}=1}^{\mathrm{n}} \sqrt{\left(\ln X_{i}-\ln X_{F}\right.}\right)^{2 / \mathrm{n}}$, donde $\mathrm{n}$ número de entidades territoriales, ${ }^{8}$ Según la fórmula:
valor en la entidad territorial $i, X r=$ Valor en la región de referencia $r$.
} 


\subsection{Macrocefalia territorial de la producción web: una evolución sin cambio}

La polarización territorial de la producción de dominios web es prácticamente un hecho corroborado en todos los países que componen el presente estudio; sin embargo, los grados que caracterizan esta concentración son dispares y significativamente diferentes de un país a otro (cuadro 3).

En promedio, casi la mitad de los dominios producidos en los países participantes en el estudio son generados en la entidad más productiva de cada nación; en la segunda y tercera entidad de la clasificación de productividad se genera la quinta parte de los dominios totales. De cara a la alta concentración que se da generalmente en las tres primeras entidades más productivas se registra una fuerte dispersión en las demás entidades que, en conjunto, representan un poco menos de la tercera parte de la producción total de los dominios nacionales.

De esta manera, las diferencias en la estructura de polarización entre países son generadas principalmente por la producción de las entidades líderes que suscitan en promedio de dos a nueve de cada 10 dominios nacionales. Estas diferencias entre países van disminuyendo y alcanzan en promedio, en la segunda y la tercera entidad, un nivel seis veces menos importante comparado con las primeras más productivas, lo que deja entrever más equidad en la participación relativa de las entidades de la clasificación inferior (cuadro 3).

En el marco de estas diferencias que caracterizan la estructura de polarización de la producción web, salvo los casos de Alemania y Brasil, todos los demás países involucrados en el estudio destacaron por contar con un capital nacional que produce el mayor número de dominios. Tanto en Alemania como en Brasil, la entidad capital ni siquiera aparece en las tres primeras entidades más productivas del país, revelando la insuficiencia del centralismo administrativo y sus poderes intrínsecos ejercidos para imprimirle a estas ubicaciones un liderazgo productivo en la web.

En este sentido, al igual que lo observado por Zook (2001) y Castells, (2002), el empoderamiento territorial de la producción web parece relacionarse con liderazgos tradicionales ejercidos en los ámbitos sociopolíticos, económicos y culturales.

Durante el periodo 1999-2009 la macrocefalia de la producción de dominios web, aproximada a través del índice de primacía que mide la relación de la producción de la primera entidad entre la producción de las tres entidades siguientes, dejó entrever una evolución ubicando a la producción paraguaya como la más polarizada de los países estudiados.

En promedio, durante el periodo de estudio la producción de la web en Paraguay fue casi dos veces más polarizada que en la Federación Rusa, 


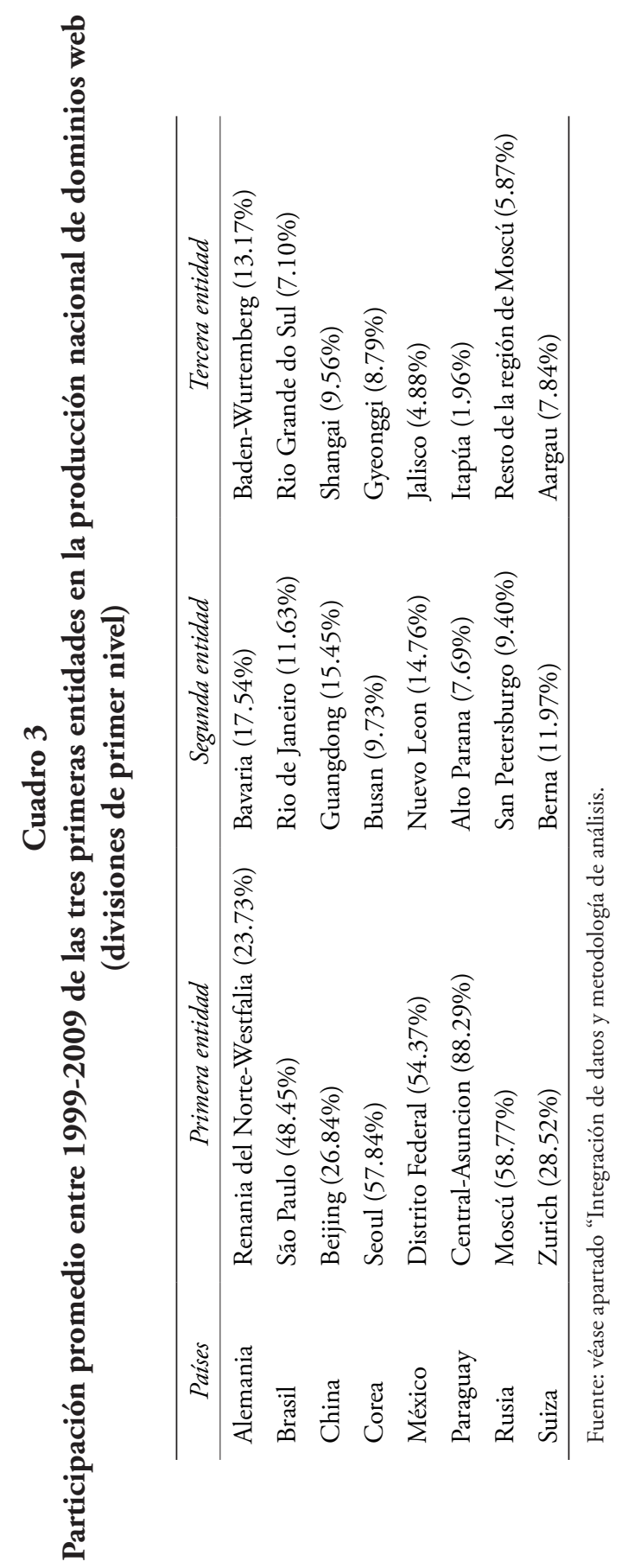


cerca de cuatro veces más que en México y Corea, 10 veces más que en Suiza y China, y finalmente, 14 veces más que Alemania, el país con la producción de dominios más descentralizada (gráfica 1).

En términos evolutivos, no parece existir en todos los casos una relación directa y lineal entre el índice de primacía y la amplitud de su variación anual registrada entre 1999-2009. En este sentido, aunque esta relación parece verificarse para el caso del extremo alto (Paraguay) y bajo (Alemania), la macrocefalia más fuerte caracteriza una amplitud de variación más grande, y la más baja se relaciona con variaciones que pueden considerarse como inerciales. No obstante, el comportamiento entre estas dos variables parece más bien imprevisible considerando el caso de China que se caracterizó por un índice de primacía bajo y una significativa amplitud en su variación anual.

La imprevisibilidad de la relación entre el nivel de la macrocefalia y su variación durante el periodo de estudio se traduce en comportamientos dispares e independientes del grado de polarización de la producción web en cada país.

En efecto, países que no presenten similitudes en sus respectivas polarizaciones como China, Suiza y Corea son caracterizados por variaciones significativas de su macrocefalia productiva, mientras que en otras naciones como Paraguay, Rusia, México, Brasil y Alemania se percibe una estagnación en la evolución de sus respectivos índices de primacía.

Esto parece indicar que aunque hubo un incremento espectacular de las producciones nacionales de 1999-2009 (cuadro 1), estos avances aprovecharon, en una medida apreciable, a la entidad que dominaba la producción en cada uno de los países involucrados en el estudio. En este sentido, a pesar del enorme esfuerzo público y privado para fortalecer la apropiación local y regional de la internet, la macrocefalia que caracterizaba a los paisajes productivos de los inicios de la web no parece haber cedido paso a una pertinente descentralización hacia la periferia.

\subsection{Una evolución que no logra revertir la dispersión de los inicios de la web}

La macrocefalia de la producción de contenidos que parece estructurar a los paisajes nacionales de la web en los países involucrados en el estudio se traduce en una intensa dispersión territorial de la misma producción. Esta dispersión se expresa en el marco de las divisiones territoriales de primer nivel a través del coeficiente de variación estandarizado durante un periodo de 10 años (1999-2009) y coloca entre el grado de dispersión más alto (Federación Rusa) y el más bajo (Alemania) a Paraguay, México, Brasil, Corea del Sur, China y Suiza. 


\section{Gráfica 1}

Evolución del índice de primacía entre 1999-2009

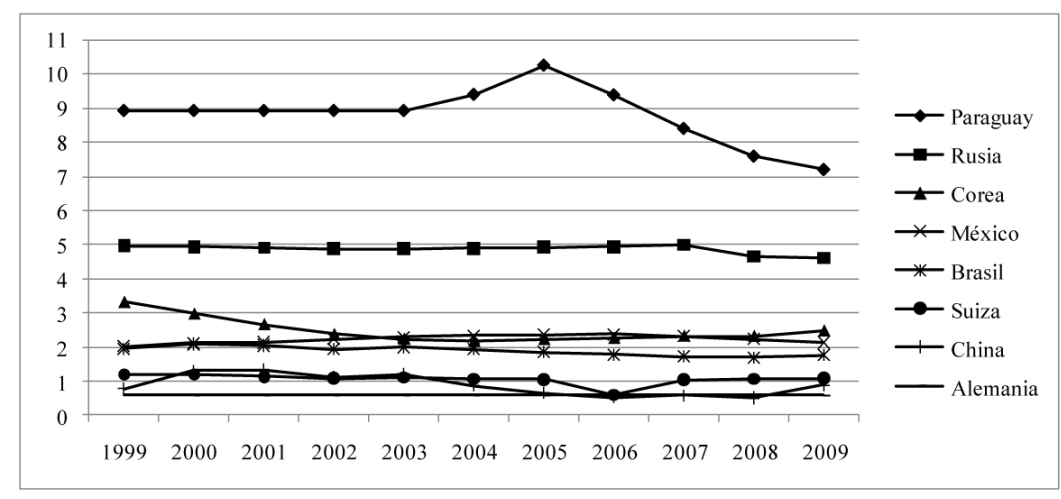

Fuente: Conteo de dominios realizado conforme a la investigación presentada en el apartado "Integración de datos y metodología de análisis”.

En términos evolutivos, salvo el caso de China que logra pasar ligeramente por debajo de Suiza entre 2006-2008, el orden de dispersión en los demás países analizados parece respetarse año tras año durante la década considerada (gráfica 2).

Desde la perspectiva del mismo posicionamiento ordinal, comparado con la dispersión promedio del número de dominios web en Alemania, destaca el caso de la Federación Rusa con una heterogeneidad territorial cinco veces más alta cuando esta última está cerca de tres veces por arriba de Paraguay y México, dos veces de Brasil y Corea, y solamente alrededor de una en China y Suiza.

Lo anterior deja entrever el distanciamiento que separa la Federación Rusa de los demás países estudiados, destacando una brecha con Paraguay, país que le sigue en un orden inmediato, equivalente a la dispersión regional promedio de China entre 1999-2009 (gráfica 2). Esta dinámica se traduce también en un agrupamiento de los países estudiados en la mitad más baja de la dispersión analizada (cv estandarizado entre 0.1 y 0.6 ), con la excepción de la Federación Rusa que ocupa una franja de la mitad más alta (Cv estandarizado entre 0.8 y 1 ).

La atipicidad que parece describir el caso de la Federación Rusa pone de relieve, entre 1999 y 2009, una desviación estándar (DE) de la dispersión regional alrededor de 22 veces más alta que en Alemania. Comparado con este último país caracterizado por la desviación más baja, China exhibe una (DE) 14 veces más alta, Brasil seis veces, Corea del Sur cuatro, México tres, y Paraguay y Suiza dos. 
En este sentido, con relación al grupo de países analizados, tanto Alemania, Suiza y Paraguay se caracterizaron entre 1999 y 2009 por un estancamiento de las diferencias de producción regional de dominios; Corea del Sur, México y Brasil presentaron algunas variaciones regulares, mientras que China y la Federación Rusa dejaron entrever amplias desviaciones en sus diferencias regionales.

Al tomar en cuenta el conjunto de las observaciones anteriores, se podrá llegar a plantear la presunción de que a mayores dispersiones en la producción regional de dominios corresponden las más altas desviaciones en la dispersión interregional. Dicho de otro modo, para los países que presentan grandes diferencias regionales en la producción de contenidos web se puede llegar presenciar a una evolución marcada por la reducción o ampliación de la dispersión inicialmente observada.

En los países estudiados, esta conjetura parece verificarse sólo en el caso extremo de la Federación Rusa, destacando además una dispersión baja en el caso de China que se encuentra identificada por la segunda desviación más alta del estudio. Bajo esta lógica, independientemente del sentido de evolución de las diferencias regionales (a la alza o a la baja), el estudio parece indicar que durante la década analizada estas dinámicas fueron generalmente insuficientes para revertir (o modificar de manera significativa) la amplitud de las dispersiones iniciales.

\subsection{Convergencia intrarregional: progresión intermitente $y$ un balance mitigado}

La dinámica de la heterogeneidad territorial de la producción de dominios web expresada por la variación de la dispersión que informan los Cv estandarizados, y analizada en el párrafo anterior, nos lleva a preguntarnos si la evolución temporal de dicha dispersión se encamina en el sentido de afianzar una situación de convergencia o divergencia territorial.

Es decir, con el tiempo estaríamos asistiendo a la reducción de las brechas en materia de producción de dominios entre las diferentes regiones del país analizado (convergencia interregional) o, por lo contrario, estas diferencias seguirían creciendo (divergencia interregional). En este orden de ideas, estas dinámicas regionales serán evaluadas por medio del índice de convergencia sigma, y el crecimiento de sus valores revelaría una divergencia territorial, mientras que una reducción de los mismos indicaría un contexto territorial convergente.

En la Federación Rusa se registró una sostenida reducción de la divergencia territorial de 1999 a 2005 y después el índice sigma se caracterizó por una cierta estagnación que mantuvo el estatus interregional en la producción de dominios hasta el 2009. Para Paraguay, el periodo 1999- 


\section{Gráfica 2}

\section{Evolución del coeficiente de variación estandarizado} entre 1999-2009

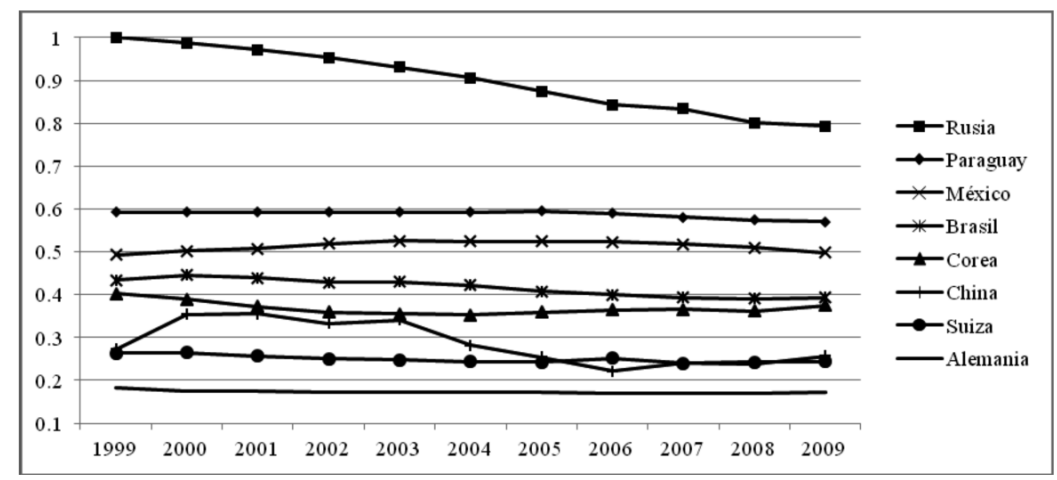

Fuentes: Conteo de dominios realizado conforme a la investigación presentada en el apartado "Integración de datos y metodología de análisis".

2003 se caracterizó por su estabilidad, mientras que de 2003 a 2007 se dio un crecimiento de las divergencias interregionales, seguido por otro periodo de estagnación hasta el 2009.

Salvo el caso de Brasil que parece dirigirse de manera paulatina pero sostenida en el marco de la convergencia interregional, México y China se caracterizaron por oscilaciones que destacan, en el caso mexicano, una tendencia hacia el incremento de la divergencia interregional a partir de 2005 y, en el caso de China, a mantener una cierta estabilidad a partir de 2007. Los demás países del estudio (Suiza, Corea del Sur y Alemania) se caracterizaron globalmente por variaciones mínimas del valor del índice de convergencia sigma durante 1999 (gráfica 3).

En promedio, entre 1999 y 2009, la divergencia interregional en el seno de la Federación Rusa fue casi dos veces más alta que en Alemania, mientras que la fluctuación de su variación anual, medida por la desviación típica durante el periodo, fue casi ocho veces más alta. Estos promedios en la divergencia interregional dejan entrever dos grandes grupos de países compuestos, de un lado, por Alemania, Corea, Suiza y China, caracterizados por promedios bajos, y del otro, Brasil, México, Paraguay y la Federación Rusa, identificados por promedios altos.

Sin embargo, en términos de fluctuación anual de esta misma divergencia intrarregional en diferentes países, las variaciones más altas se relacionan con Rusia, Paraguay y México, las medianas con China y Brasil, $y$, finalmente, las bajas con Suiza, Corea y Alemania.

Todo esto parece indicar que, más allá del efecto suavizador de la evolución promedio de la divergencia interregional durante el periodo de 


\section{Gráfica 3}

Evolución del índice de convergencia sigma entre 1999-2009

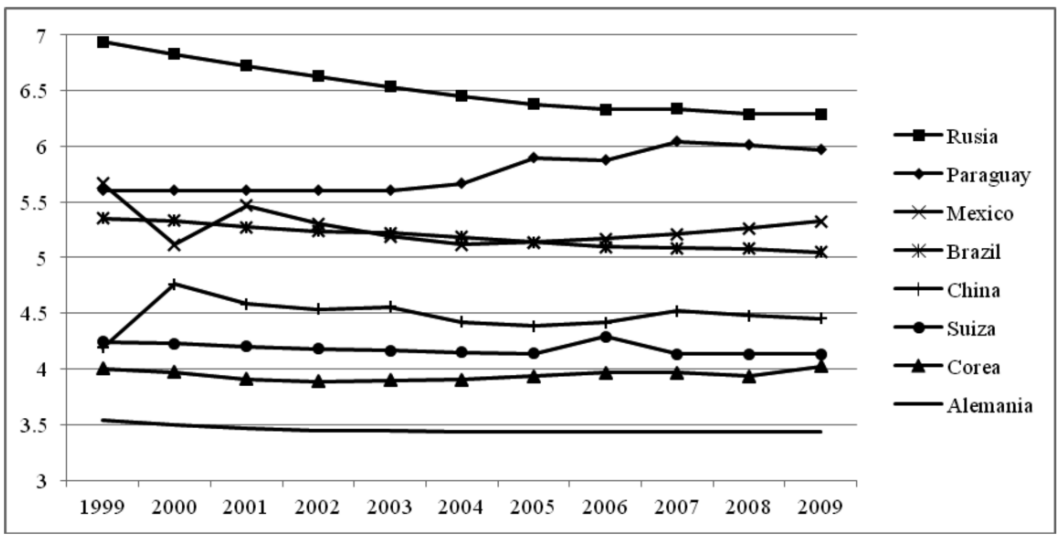

Fuentes: Conteo de dominios realizado conforme a la investigación presentada en el apartado "Integración de datos y metodología de análisis".

estudio, su fluctuación anual introduce otro tipo de segmentación en los países estudiados.

Lo anterior parece corroborar que a mayor convergencia corresponde una menor fluctuación interregional y viceversa, deducción que no parece desmentir el caso de China a pesar de registrar una desviación anual más alta que Brasil, el cual se caracteriza por una convergencia promedio más baja en comparación con el país asiático.

Tomando en cuenta los resultados, la bifurcación entre países desarrollados y emergentes analizados en este estudio como posible línea de explicación de la polarización territorial de la producción web deja lugar a una manifestación diferenciada por las propias trayectorias de evolución.

\subsection{Dualidad contextual desarrollado-emergente y trayectorias de evolución dispares}

El análisis de la producción web, desde una perspectiva dual de países desarrollados caracterizados por una baja polarización territorial y de otros emergentes identificados por una pronunciada concentración de la misma, no parece sostenerse rotundamente en el presente estudio. Justamente, a pesar de que los países que se identificaron por los más bajos indicadores de polarización están generalmente ubicados en el seno del grupo de los desarrollados, y los más altos en los países emergentes, esta afirmación está lejos de corroborarse para la totalidad de los países analizados. 
En el caso de China es emblemático que, siendo un país emergente, su estructura de polarización se ubique justo atrás de Alemania (caracterizada por la producción territorial más descentralizada) adelantando a todos los demás países involucrados en el estudio, incluyendo a Suiza.

Con una macrocefalia estructural y una dispersión territorial de la producción web semejante a lo observado en países desarrollados del estudio, China se caracteriza por mostrar una importante variación temporal de dicha dispersión que se refleja también en el marco de una tendencia, confirmada en los países desarrollados, para reducir la brecha de producción entre sus diferentes regiones.

De hecho, esta última cualidad identificada en los países emergentes (salvo el caso de Corea), se caracteriza por su macrocefalia y por la dispersión territorial de sus producciones, contextos propicios que destacan la reducción de las desigualdades interregionales, y se comparan con variaciones marginales que definen a los países con una participación territorial más equilibrada.

En este sentido, China exhibe particularidades mixtas, unas propias de los países desarrollados y otras de los emergentes, con lo que destaca la posibilidad de un caso híbrido que aprovecha lo mejor que define a cada uno de los dos grupos de países.

No obstante, lo visto en el caso de China contrasta con la situación de su vecino continental, Corea, que se caracteriza por una macrocefalia justo detrás de los países con alta polarización (Paraguay y Rusia), así como por una dispersión territorial de la producción y una variación temporal mayor, aunque la tendencia para reducir la brecha de producción entre sus diferentes regiones está igual de estancada que en el caso de los países desarrollados como Alemania y Suiza.

De este modo, Corea parece evolucionar en medio de un esquema territorial de producción web también híbrido pero tipificado por las características no deseables que definen a ambos grupos de países (desarrollados y emergentes).

Entre los casos de China y Corea que parecen modelos atípicos, se colocan tres grupos de países definidos por las parejas de naciones siguientes: Paraguay y Rusia, México y Brasil, Suiza y Alemania.

El primer grupo se definió con la más alta polarización y macrocefalia de la producción web entre 1999 y 2009, cuando Rusia se distinguió hasta el 2004 por una reducción continua de las desigualdades interregionales, seguido por un un leve estancamiento; en Paraguay la macrocefalia fue exageradamente más alta, impactando en un sensible crecimiento de las diferencias interregionales a partir del 2003.

El grupo de Brasil y México se caracterizó por un perfil promedio de polarización y macrocefalia que fue traducido, en el caso de México, por 
la alternancia de periodos de achicamiento y ampliación de las diferencias interregionales.

Por lo contrario, Brasil mostró un desempeño determinado por periodos de reducción y otros de estancamiento de las diferencias interregionales. Sin embargo, en ambos países las oscilaciones de las diferencias interregionales fueron bajas considerando las fuertes fluctuaciones observadas en el caso de Rusia y Paraguay.

Por último, el grupo conformado por Alemania y Suiza destacó por un contexto de polarización y macrocefalia de los más bajos del estudio y un estancamiento casi perfecto en el caso de Alemania, en la reducción de las diferencias interregionales. Lo anterior parece fortalecer la afirmación que sustenta que las condiciones de cercanía a la equidad de la participación interregional de producción de la web se traducen en una fluctuación marginal de la convergencia interregional.

\section{Conclusiones}

El importante y sostenido crecimiento del número de dominios web nacionales en los países involucrados en el estudio deja entrever una estructura de polarización que no ha logrado deshacerse de las inercias que le han dificultado conseguir las condiciones de una producción descentralizada.

En efecto, a pesar de la colosal producción de contenidos que vino a ensanchar la oferta consultable por los internautas, la situación evolutiva de los países involucrados en el estudio muestra una web que sigue generándose principalmente en ubicaciones que llegan a confundirse con entidades de dominante jerarquía urbana y metropolitana.

Con el objetivo de ampliar los indicadores de penetración y apropiación productiva de la internet, durante la década que enmarca el periodo de estudio (1999-2009), se asistió a la formulación de políticas nacionales y a la aplicación de un impresionante número de planes, programas y proyectos.

El imperativo de la inserción socioterritorial a la sociedad de la información ha ido transformándose en eje de acción para aquéllos que tienen en sus manos la posibilidad de tomar decisiones respecto al tema, y un estimulo renovado para actores provenientes de diversos ámbitos de la representación social.

No obstante, el conjunto de estas estrategias, políticas y acciones no se tradujo en una tajante descentralización de la producción hacia las ubicaciones periféricas. De hecho, la fuerte polarización territorial que sigue identificando a la producción de contenidos web deja entrever una 
ausencia de la vertiente territorial en la estructuración de las políticas y acciones encaminadas a lidiar con la brecha digital.

La dimensión territorial de la brecha digital en los países involucrados en el estudio que puede llegar a expresar la macrocefalia de la producción web, se observa en su persistencia en el tiempo y en la imprevisibilidad de su comportamiento. En este sentido, salvo los casos de Alemania y Brasil que sustentan un tipo de interacción diferente con su capital nacional, todos los demás países involucrados en el estudio siguen produciendo el mayor número de sus dominios en sus respectivas ciudades capitales.

De esta manera, las estrategias de actores que contemplaron alcanzar una mayor convergencia intrarregional, con el paso del tiempo, no lograron la suficiente producción web en las entidades periféricas para revertir la amplitud de las dispersiones territoriales iniciales. Estas últimas, en el caso de los países que fueron caracterizados por altas dispersiones, permanecen en niveles muy elevados expresando a veces a diferencias profundas como las exhibidas en el marco de la evolución productiva de la Federación Rusa.

Con tales resultados, el enfoque dual desde la perspectiva de países desarrollados y emergentes no parece aportar mayor sustancia para el entendimiento de la problemática de la polarización territorial de la producción web. En efecto, tomando en cuenta lo observado en los países involucrados en el estudio, lo que más resalta es un comportamiento diferencial que puede llegar, en los casos atípicos de China y Corea, a exhibir un modelo de producción híbrido con características tanto de países desarrollados como emergentes.

Dentro de la atipicidad que arrojan los dos países citados anteriormente, destacan Rusia y Paraguay por presentar a un perfil productivo altamente consolidado en sus entidades capitales. México y Brasil alternarnan periodos de concentración y de distribución y, finalmente, Suiza y Alemania parecen coincidir con una baja polarización y estancada descentralización.

Sin embargo, más allá de las enseñanzas que se desprenden del estudio de la relación entre la producción de contenidos y su ubicación geográfica, resulta importante para la reflexión y la acción deslindar los motivos que hicieron que las políticas y la acción de fomento de la apropiación productiva de las TIC tengan poco éxito en la descentralización de la producción web.

\section{Bibliografía}

Antonelli, Cristiano (1986), L'attività innovativa in un distretto tecnologico, Fondazione Agnelli, Torino. 
Bertrand, Nathalie (2001), "Technologies d'information et de communication: quel rôle dans les dynamiques territoriales et les processus de développement", Revue d'Economie Regionale et Urbaine, 1, Université Montesquieu-Bordeaux IV, Bordeaux, pp. 135-152.

вм (Banco Mundial) (2005), Equity and development: world development report 2006, World Bank, Washington, DC.

Cairncross, Frances (1997), The death of distance, Harvard University Press, Cambridge.

Cairncross, Frances (2001), The death of distance 2.0, how the communications revolution will change our lives, Texere, London.

Castells, Manuel (2002), The internet galaxy. Reflexion on the internet, business and society, Oxford University Press, Oxford.

Castells, Manuel (2003), The power of identity, Blackwell, Oxford.

Denardis, Laura (2014), The global war for internet governance, Yale University Press, New Haven.

Dodge, Martin y Narushige Shiode (2000), "Where on the earth is the internet? An empirical investigation of the geography of the internet", en James Wheeler, Yuko Aoyama y Warf Barney (coords.), Cities in the telecommunications age. The fracturing of geographies, Routledge, London, pp. 42-53.

Dodge, Martin y Rob Kitchin (2001), Mapping cyberspace, Routledge, Londres.

Dosi, Giovanni (1988), Technical change and economic theory, Pinter Pub Ltd., London.

Escobar, Arturo (1995), "Imagining a post-development era", en Jonathan Crush (coord.), Power of development, Routledge, London, pp. 211-227.

Esteva, Gustavo (1987), "Regenerating people's space", Alternatives. Global, local, political, XII (198), University of Waterloo, Ontario, pp.125-152. 
Eveno, Emmanuel (1997), "Pour une géographie de la société de l'information”, Netcom, 11, IGU-CNFG, Montpellier, pp. 431-457.

Forman, Chris, Avi Goldfarb y Shane Greenstein (2005), "How did location affect adoption of the commercial internet? Global village vs urban leadership", Journal of Urban Economics, 58 (3), Elsevier, New York, pp. 389-420.

Gaspar, Jess y Edward Glaeser (1998), "Information technology and the future of cities”, Journal of Urban Economics, 43 (1), Elsevier, New York, pp. 136-56.

Graham, Stephen y Simon Marvin (1996), Telecommunications and the city: electronic spaces, urban places, Routledge, London.

Graham, Stephen (1998), "The end of geography or the explosion of place? Conceptualizing space, place and information technology", Progress in Human Geography, 22 (2), sage Publications, Thousand Oaks, pp. 165-185.

Graham, Stephen y Simon Marvin (2001), Splintering urbanism. Networked infraestructures tecnological mobilities and the urban conditions, Routledge, London.

Graham, Mark (2008), "Warped geographies of development: the internet and theories of economic development", Geography compass, 2 (3), Blackwell Publishing, Oxford, pp. 771-789.

Greenstein, Shane (2006), “The economic geography of internet infrastructure in the United States", en Martin Caves, Sumit Majumdar e Ingo Vogelsang (coords.), The Handbook of Telecommunications Economics, vol. II, Elsevier, Amsterdam, pp. 287-372.

Grimes, Seamus (2003), "The digital economy challenge facing peripheral rural areas”, Progress in Human Geography, 27 (2), SAGE Publications, Thousand Oaks, pp. 174-193.

Hashimoto, Kenji (2002), "Restructuring of distribution system with innovation of IT: a case study of wholesale industries in Japan”, Netcom, 17 (3-4), IGU-CNFG, Montpellier, pp. 203-214. 
Kellerman, Aharon (1985), "The evolution of service economies: a geographical perspective", The Professional Geographer, 37 (2), Association of American Geographers, Washington, DC, pp. 133-143.

Kellerman, Aharon (2002), The internet on earth. A geography of information, Wiley, Chichester.

Keniston, Kenneth y Deepak Kumar (eds.) (2004), It experience in India. Bridging the digital divide, sage Publishers, Delhi.

Kolko, Jed (2000), "The death of cities? The death of distance? Evidence from the geography of commercial internet usage", en Ingo Vogelsang y Benjamin Compaine (coords.), The internet upheaval, мiт Press, Cambridge, pp. 73-98.

Massey, Doreen (2005), For space, sage Publishers, London.

Masuda, Yoneji (1980), The information society as post-industrial society, World Future Society, Washington, DC.

Moss, Mitchell y Anthony Townsend (1997), "Tracking the net: using domain names to measure the growth of the internet in U.s. cities", Journal of Urban Technology, 4 (3), Routledge, London, pp. 47-60.

Moss, Mitchell y Anthony Townsend (2000), "The internet backbone and the american metropolis", Information Society, 16 (1), Routledge, London, pp. 35-47.

Norris, Pippa (2001), Digital divide: civic engagement, information poverty, and the internet worldwide, Cambridge University Press, Cambridge.

Paradiso, Maria y Viviana d'Aponte (2003), "Virtual urban geographies in Italy and traditional-digital places interlinkage", Netcom, 17 (3-4), IGU-CNFG, Montpellier, pp. 215-247.

Schech, Susanne (2002), "Wired for change: the links between ICTs and development discourses", Journal of International Development, 14 (1), Wiley, New Jersey, pp.13-23.

Schmidt, Andreas (2013), “The Estonian cyberattacks”, en Jason Healey (ed.), A fierce domain: conflicts in cyberspace, 1986 to 2012, 
Atlantic Council-Cyber Conflict Studies Association, Vienna, Virginia.

Schmidt, Andreas (2014), "Hierarchies in networks: emerging hybrids of networks and hierarchies for producing internet security", en Jan-Frederik Kremer y Benedikt Müller (eds.), Cyberspace and International Relations: Theory, prospects and challenges, Springer, Berlin, pp.181-202.

Stimson, Robert, Roger Stough y Maria Salazar (2009), Leadership and institutions in regional endogenous development, Edward Elgar Publishing Limited, Northampton.

Toudert, Djamel (2003), "La integración telemática en México: algunos límites y contradicciones de la planeación centralizada", Región y Sociedad, XV (28), El Colegio de Sonora, Hermosillo, pp. 193223.

Toudert, Djamel y Gustavo Buzai (2004), Cibergeografía. Tecnologías de la información y las comunicaciones (TIC) en las nuevas visiones espaciales, Universidad Autónoma de Baja California, Mexicali.

Toudert, Djamel (2005), "El ciberespacio, territorios y territorialidad en México", ponencia presentada en el Coloquio Fronteras y Poderes en América Latina, Centro de Investigación y Documentación sobre América Latina-CRedAL-CNRs, 20-21 de junio, París.

Toudert, Djamel (2007), "Algunos rasgos y particularidades de la polarización territorial de la producción de contenidos web en México", Economía, Sociedad y Territorio, VII (23), El Colegio Mexiquense, A.c., Zinacantepec, pp. 579-611.

Toudert, Djamel, Norma Fimbres y Felipe Cuamea (2008), "Las redes de innovación en la producción de contenidos web en México: un acercamiento empírico desde la perspectiva territorial y vocacional”, Región y Sociedad, XX (43), El Colegio de Sonora, Hermosillo, pp. 131-161.

Townsend, Anthony (2003), "Wired/Unwired: the urban geography of digital networks", PhD, dissertation, Massachusetts Institute of Technology, Cambridge. 
Wilson, Mark y Kenneth Corey (2000), Information tectonics: space, place and technology in an electronic age, Wiley, London.

Zook, Matthew (2000), "Internet metrics: using hosts and domain counts to map the internet globally", Telecommunications Policy, 24 (6-7), Elsevier, New York, pp. 613-620.

Zook, Matthew (2001), "Old hierarchies or new networks of centrality? The global geography of the internet content market", American Behavioral Scientist, 44 (10), sage Publications, Thousand Oaks, pp. 1679-1696.

Zook, Matthew (2005), The geography of the internet industry: venture capital, dot-coms, and local knowledge, Blackwell Publishers, London.

Zook, Matthew y Mark Graham (2007), “The creative reconstruction of the Internet: Google and the privatization of cyberespace and digiplace", Geoforum, 38, Elsevier, New York, pp. 1322-1343.

Recibido: 2 de junio de 2011. Reenviado: 7 de noviembre de 2011. Aceptado: 13 de marzo de 2012.

Djamel Toudert. Es doctor en geografía, urbanismo y ordenamiento territorial por el Instituto de Altos Estudios de América Latina, Universidad de París 3. Actualmente labora en el Departamento de Estudios Urbanos y Medio Ambiente de El Colegio de la Frontera Norte. Sus actuales líneas de investigación son: apropiación socioterritorial de las Tecnologías de la Información y las Comunicaciones (TIC). Entre sus últimas publicaciones se encuentran: "La brecha digital en los contextos de marginación socioterritorial de las localidades mexicanas de más de 2,500 habitantes: Exploración y discusión”, Comunicación y Sociedad, 19, Universidad de Guadalajara, Guadalajara, pp. 153-180 (2013); en coautoría "La participación social en el ordenamiento ecológico: Integración y procesamiento en el caso de Baja California”, en Francisco Ferrando A. (ed.), Anales de la sociedad chilena de Ciencias Geográficas 2011, Sociedad Chilena de Ciencias Geográficas, Santiago de Chile, pp. 246-252 (2012); "Some elements to discuss the agrarian morphology asymmetry in the Mexicali-Imperial border region", Ambiente y Desarrollo, XVI (30), Pontifica Universidad Javeriana, Bogotá, pp. 9-19 (2010). 